
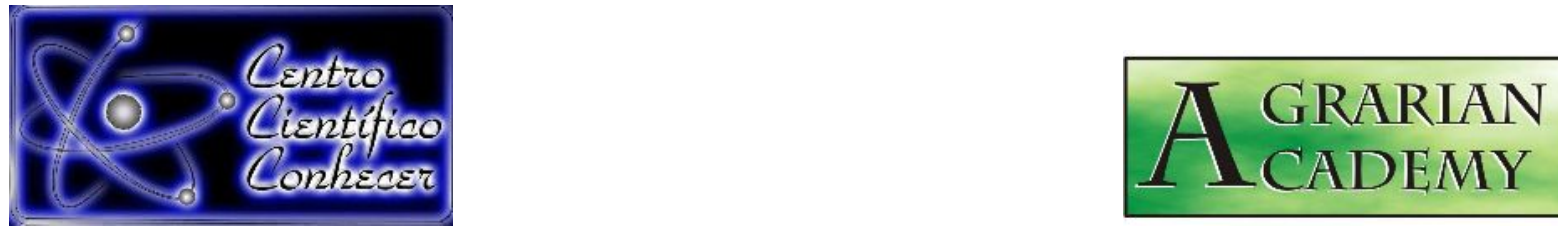

\title{
PERFIL SÓCIO-ECONÔMICO DOS PRODUTORES DE MUDAS CÍTRICAS DE UMA COMUNIDADE EM CAPITÃO POÇO, PA
}

\footnotetext{
Nayane da Silva Souza ; Ironeide Lima e Lima²; Maria Kalyane Farias da Silva²; Heráclito Eugênio Oliveira da Conceição ${ }^{3}$

${ }^{1}$ Mestranda em Fitopatologia, Universidade Federal de Lavras, Lavras, MG, Brasil. (nayanesouza42@gmail.com).

${ }^{2}$ Engenheira Agronôma, Universidade Federal Rural da Amazônia, Campus Capitão Poço, Capitão Poço, PA, Brasil.

${ }^{3}$ Professor Doutor da Universidade Federal Rural da Amazônia, Campus Capitão Poço, Capitão Poço, PA, Brasil.
}
Recebido em: 19/11/2018 - Aprovado em: 14/12/2018 - Publicado em: 25/12/2018 DOI: 10.18677/Agrarian_Academy_2018B14

\begin{abstract}
RESUMO
O objetivo do presente trabalho foi realizar o levantamento das principais características de produção, a partir de informações dos produtores de mudas cítricas em uma comunidade de Capitão Poço, no Estado do Pará. O estudo foi realizado nos meses de junho e julho de 2016, onde os dados foram coletados por meio de questionário semiestruturado abrangendo questões referentes aos aspectos socioeconômicos dos produtores e aspectos produtivos do cultivo de mudas cítricas. Os dados obtidos foram plotados para planilha Excel e realizada a estatística descritiva dos mesmos. O diagnóstico da produção de mudas cítricas na região indica que grande parte dos problemas enfrentados pelos produtores de mudas cítricas são de orden econômica, tecnológica, gerencial e de qualificação profissional no interior das unidades produtivas, o que acarreta em dificuldades principalmente para a adequação a legislação vigente, carecendo assim, de soluções consistentes.

PALAVRAS-CHAVE: Cultivo, Diagnóstico, Legislação, Questionário.
\end{abstract}

\section{PROFILE ECONOMIC AND SOCIAL OF PRODUCERS OF CITRUS SEEDLINGS IN A COMMUNITY OF CAPITÃO POÇO, PARÁ.}

\begin{abstract}
The objective of present work was to investigate of main production characteristics, based on information from citrus seedlings producers in a community Capitão Poço, state Pará. The survey was conducted carried out between to months June and July of the year 2016, where the data were collected through in semi - structured questionnaire covering issues related to socioeconomic aspects of growers and productive aspects in cultivation of citrus seedlings. The data were transferred to
\end{abstract}


Excel spreadsheet and it was realized descriptive statistics of information. The diagnosis of production of citrus seedlings in region indicates that most of problems faced seedlings producers are order economic, technological, managerial and professional qualification within productive units, which causes difficulties mainly to suit current legislation, thus need consistent solutions.

KEYWORDS: Cultive, Diagnostic, Legislation, Questionnaire.

\section{INTRODUÇÃO}

O município de Capitão Poço no nordeste paraense, possui uma população correspondente a 51.889 habitantes. A cidade possui uma área de $272.745,99 \mathrm{~km}^{2}$, e a economia baseia-se fortemente na agricultura familiar, com destaque para a produção de laranja. O município tem demonstrado potencial no desenvolvimento agrícola devido à expansão dos cultivos de laranja, pimenta-do-reino, pecuária e outros (IBGE, 2015).

Sabe-se que o sucesso da produção de uma cultura de interesse está relacionado, principalmente, a implantação da mesma, que vai desde a escolha do terreno até a colheita. Uma das grandes problemáticas da citricultura é a produção de mudas de qualidade, livre de patógenos e que garanta o sucesso do plantio. Para Souza et al. (1995) a produção da muda, de qualquer cultura, é a fase mais importante para o sucesso do cultivo, pois uma muda malformada e debilitada, por qualquer fator que seja, compromete todo o desenvolvimento da cultura.

$\mathrm{Na}$ produção de mudas de qualidade aspectos fundamentais devem ser observados como à garantia genética, os métodos de propagação, os sistemas de produção e à legislação vigente (EFROM;SOUZA, 2018), com o objetivo de garantir mudas livres de incidência de doenças e pragas, proteger o potencial genético e garantir plantas sadias e de alta produção.

Desenvolver pesquisas do tipo se torna primordial, para potencializar a produção agrícola. Conhecer o perfil dos produtores de mudas, suas necessidades e dificuldades produtivas está relacionado diretamente com o desencadeamento de criação de políticas públicas para maximizar a produção citrícola no município, uma vez que se trata de uma atividade que gera emprego e renda para um grande número de famílias. Uma média de 30 mil empregos diretos e indiretos temporariamente são gerados no município, cerca de $60 \%$ da população, segundo dados do IBGE (2015).

Diversos trabalhos através de questionários têm demonstrado resultados significativos, uma vez que o mesmo caracteriza o perfil de uma determinada comunidade relacionada a um determinado assunto. Silva (2017) realizando trabalho com estruturas semelhantes, através da técnica Snow Ball (Bola de Neve) conseguiu caracterizar o perfil socioeconômico de agricultores familiares em um assentamento no Estado da Paraíba.

Já Freitas e Wander (2017), realizaram levantamento do perfil socioeconômico de produtores familiares de hortaliças no município de Anápolis, em Goiás. Através desse estudo, os autores permitiram a criação de dados de interesse ao poder público, uma vez que os mesmos podem ser ferramentas para subsídio a agricultura familiar do município.

Assim, o levantamento sócio econômico de um determinado assunto permite o pesquisador levantar dados importantes para que sejam tomadas as decisões com intuito de melhorar a vida de uma comunidade, seja esta no âmbito rural ou não. 
Espera-se que, o presente trabalho sirva de ferramenta no auxílio de estudos e pesquisas da natureza. Neste sentido, o objetivo do presente trabalho foi compreender as principais características de produção, a partir de informações dos produtores de mudas cítricas em uma comunidade de Capitão Poço, no Estado do Pará.

\section{MATERIAL E MÉTODOS}

Os dados deste trabalho foram coletados na comunidade de Santa Luzia do Induá, distante $13 \mathrm{Km}$ do município de Capitão Poço, Pará. A comunidade é considerada a maior produtora de mudas cítricas do estado do Pará. O município de Capitão Poço está localizado nas coordenadas 0144'47" Sul 470'ㄷㄱ" e Oeste, a $73 \mathrm{~m}$ de altitude. O clima da região é do tipo Ami segundo a classificação de Köppen, apresenta temperatura média anual de $26,90{ }^{\circ} \mathrm{C}$ e precipitação pluviométrica anual de 2.499mm (PACHECO;BASTOS, 2002).

O estudo foi realizado nos meses de junho e julho de 2016, sendo os dados coletados pelos autores por meio de questionário semiestruturado totalizando 25 perguntas abertas e fechadas, abrangendo questões referentes aos aspectos socioeconômicos dos produtores e aspectos produtivos no cultivo de mudas cítricas, bem como as maiores dificuldades enfrentadas durante o processo de produção.

A identificação dos produtores de mudas foi feita com base na metodologia Bola de Neve (SnowballSampling), que consiste em uma técnica de amostragem não-probabilística que é aplicada por pesquisadores para identificar potenciais sujeitos em estudos onde os sujeitos são difíceis de localizar (DELUQUI et al., 2012). A partir da identificação do primeiro produtor através desta metodologia, foi possível identificar os outros, totalizando assim, uma amostra de 21 produtores entrevistados.

O levantamento serviu de base para caracterizar aspectos socioeconômicos dos produtores como: sexo, idade, estado civil, naturalidade, renda familiar, grau de escolaridade, situação da terra, participação em associações ou sindicatos, recebimento de assistência técnica, credenciamento das mudas produzidas, principais pragas e doenças, tipo de controle empregado nas doenças e pragas, quantidade de mudas produzidas durante o ano, tipos de mudas cítricas,, tipo de porta enxerto, destino da produção, tamanho da área de cultivo, estrutura dos viveiros, tipos de recipientes para produção das mudas, sistema de irrigação empregado, fonte de água utilizada na irrigação as maiores dificuldades para o aumento da produção. Os dados foram plotados para planilha eletrônica Excel sendo realizada estatística descritiva das informações contidas.

\section{RESULTADOS E DISCUSSÕES}

De acordo com a avaliação dos dados obtidos com os questionários aplicados, observou-se que $80 \%$ dos produtores de mudas cítricas entrevistados são casados, sendo a maioria do sexo masculino e com média de idade de 17 a 77 anos. Muitos desses produtores são oriundos do estado do Ceará. A maioria desses produtores são donos da terra destinada a atividades agrícolas e 38\% trabalham em terra cedida por terceiros. O nível de escolaridade da maioria dos agricultores se limita ao ensino fundamental incompleto, e destas famílias, cerca de $62 \%$ têm renda mensal inferior a um salário mínimo e que para $72 \%$, a produção de mudas corresponde a principal fonte de renda destes Os detalhes são melhores visualizados na Tabela 1.

AGRARIAN ACADEMY, Centro Científico Conhecer - Goiânia, v.5, n.10; p. 1422018 
TABELA 1 - Perfil dos produtores de mudas cítricas em Santa Luzia do Induá, Capitão Poço-Pa.

\begin{tabular}{|c|c|c|c|}
\hline Variáveis & Categorias & Frequência (n=21) & $\begin{array}{l}\text { Porcentagem } \\
(\%)\end{array}$ \\
\hline \multirow{2}{*}{ Sexo } & Masculino & 20 & 95,24 \\
\hline & Feminino & 01 & 4,76 \\
\hline \multirow{4}{*}{$\begin{array}{l}\text { Faixa Etária } \\
\text { (anos) }\end{array}$} & $17-30$ & 02 & 9,52 \\
\hline & $31-40$ & 06 & 28,57 \\
\hline & $41-77$ & 13 & 61,91 \\
\hline & Casado (a) & 17 & 80,00 \\
\hline \multirow{3}{*}{ Estado Civil } & Solteiro (a) & 04 & 20,00 \\
\hline & Separado (a) & - & - \\
\hline & Viúvo (a) & - & - \\
\hline \multirow{2}{*}{ Naturalidade } & Pará & 12 & 57,15 \\
\hline & Ceará & 09 & 42,85 \\
\hline \multirow[t]{5}{*}{ Escolaridade } & Analfabeto (a) & 01 & 4,76 \\
\hline & $\begin{array}{l}\text { Ens. Fund. } \\
\text { incompleto }\end{array}$ & 16 & 76,19 \\
\hline & $\begin{array}{l}\text { Ens. Fund. } \\
\text { Completo }\end{array}$ & 02 & 9,53 \\
\hline & $\begin{array}{l}\text { Ens. Médio } \\
\text { Completo }\end{array}$ & 01 & 4,76 \\
\hline & $\begin{array}{l}\text { Ens. Superior } \\
\text { completo }\end{array}$ & 01 & 4,76 \\
\hline \multirow[t]{3}{*}{ Renda familiar } & $\begin{array}{l}\text { Até } 1 \text { salário } \\
\text { mínimo }\end{array}$ & 13 & 61,90 \\
\hline & $\begin{array}{c}\text { De } 1 \text { a } 2 \text { salários } \\
\text { mínimos }\end{array}$ & 06 & 28,58 \\
\hline & $\begin{array}{c}\text { < de } 2 \text { salários } \\
\text { mínimos }\end{array}$ & 02 & 9,52 \\
\hline \multirow{2}{*}{$\begin{array}{l}\text { As mudas } \\
\text { correspondem a } \\
\text { única fonte de } \\
\text { renda }\end{array}$} & Sim & 06 & 28,57 \\
\hline & Não & 15 & 71,43 \\
\hline \multirow{2}{*}{$\begin{array}{c}\text { Situação da } \\
\text { terra }\end{array}$} & Própria & 13 & 61,90 \\
\hline & Cedida & 08 & 38,10 \\
\hline
\end{tabular}

Fonte: Autores (2016) 
Dos entrevistados, apenas $42,83 \%$ fazem parte de associação ou sindicato. Cerca de $52,38 \%$ dos entrevistados recebem assistência técnica de órgãos públicos como a Empresa de Assistência Técnica e Extensão Rural (EMATER), enquanto que $47,62 \%$ não recebem nenhum tipo de assistência técnica durante a produção. Do total, $57,14 \%$ destes produtores não são credenciados pelo Ministério da Agricultura, Pecuária e Abastecimento (Tabela 2). A comercialização de mudas certificadas deve ser levada em consideração, uma vez que é uma garantia de material devidamente certificado e reconhecido pelos órgãos públicos, além de passar confiabilidade para o agricultor final, que estará adquirindo material de origem conhecida.

TABELA 2 - Aspecto social dos produtores de mudas cítricas em Santa Luzia do Induá, Capitão Poço-Pa.

\begin{tabular}{cccc}
\hline Variáveis & Categorias & Frequência $(\mathrm{n}=21)$ & Porcentagem $(\%)$ \\
\hline Participa de alguma & Sindicato & 03 & 14,29 \\
organização & Associação & 06 & 28,57 \\
Necebe Assistência & Sim & 12 & 57,14 \\
Técnica & Não & 11 & 52,38 \\
& & 10 & 47,62 \\
Produz mudas & Sim & 12 & 57,14 \\
credenciadas pelo & Não & 09 & 42,86 \\
MAPA & &
\end{tabular}

Fonte: Autores (2016)

Mais de $85,71 \%$ dos entrevistados afirmaram a presença de larva minadora como principal praga das mudas citrícolas produzidas (Tabela 3). A larva minadora ataca brotações novas de todas as variedades cítricas, através da deposição de ovos nas folhas novas, de onde emerge a larva, que se alimenta da folha formando galerias, ocasionado a queda prematura destas (SÁ, 2005). A larva minadora (Phyllocnistis citrella Stainton) cria galerias nas folhas o que pode servir de porta de entrada para o cancro cítrico (BRUGNARA et al., 2015).

TABELA 3 - Pragas e doenças nos viveiros de mudas cítricas de Santa Luzia do Induá, Capitão Poço-Pa.

\begin{tabular}{cccc}
\hline Variáveis & Categorias & Frequência $(\mathrm{n}=21)$ & Porcentagem $(\%)$ \\
\hline \multirow{2}{*}{ Principais } & Formiga & 13 & 61,90 \\
Pragas & Larva minadora & 18 & 85,71 \\
& Pulgão & 14 & 66,66 \\
& Não há pragas & 01 & 4,76 \\
Principais & Gomose & 14 & 66,66 \\
doenças & Verrugose & 10 & 47,62 \\
& Não há doenças & 05 & 23,80 \\
\hline
\end{tabular}

Fonte: Autores (2016)

Ainda na Tabela 3 , estão os dados das principais pragas relatadas pelos produtores, estando o pulgão presente na maioria dos viveiros de Santa Luzia do Induá. Este inseto causa sérios danos às plantas e seu ataque é caracterizado pela AGRARIAN ACADEMY, Centro Científico Conhecer - Goiânia, v.5, n.10; p. 1442018 
sucção da seiva e encarquilhamento das folhas, podendo levar a planta à morte (LOPES et al., 2009). Já a gomose, causada pelo fungo do gênero Phytophtora, está presente em $66,66 \%$ dos viveiros. A gomose tem início com o aparecimento de manchas pardas na região do colo das plantas cítricas, evoluindo para o apodrecimento da casca, depois formando os cancros que irá exsudar uma substância similar a goma (SOMBRA et al., 2018).

De todos os agricultores consultados que afirmaram a presença dessas pragas e doenças nos viveiros, informaram que o método de controle empregado é o químico, produtos estes comprados, na maioria das vezes sem a prescrição de profissional habilitado. É sabido que aplicação de produtos químicos na agricultura sem a prescrição de um agrônomo ou qualquer outro responsável, podem trazer danos ambientais e a saúde humana.

$\mathrm{Na}$ Tabela 4 estão os dados quantitativos de mudas cítricas produzidas ao ano, variedades e principais porta-enxertos utilizados pelos produtores de mudas de Santa Luzia do Induá.

TABELA 4 - Quantidade de mudas produzidas/ano, tipos de mudas produzidas e porta enxerto.

\begin{tabular}{|c|c|c|c|}
\hline Variáveis & Categorias & Frequência $(n=21)$ & Porcentagem (\%) \\
\hline \multirow{3}{*}{$\begin{array}{l}\text { Quant. Mudas } \\
\text { produzidas/ano }\end{array}$} & Até 5 mil mudas & 06 & 28,57 \\
\hline & $\begin{array}{l}\text { de } 5,1 \text { a } 50 \text { mil } \\
\text { mudas }\end{array}$ & 13 & 61,90 \\
\hline & $\begin{array}{l}<50 \text { mil mudas } \\
\text { Apenas } \\
\text { tangerina }\end{array}$ & $\begin{array}{l}02 \\
-\end{array}$ & $\begin{array}{l}9,52 \\
-\end{array}$ \\
\hline \multirow{3}{*}{$\begin{array}{l}\text { Mudas } \\
\text { produzidas }\end{array}$} & $\begin{array}{c}\text { Apenas laranja } \\
\text { Apenas limão }\end{array}$ & $\begin{array}{l}05 \\
07\end{array}$ & $\begin{array}{l}23,81 \\
33,33\end{array}$ \\
\hline & $\begin{array}{l}\text { Limão, laranja e } \\
\text { tangerina }\end{array}$ & 07 & 33,33 \\
\hline & Limão e laranja & 02 & 9,52 \\
\hline Porta enxerto & $\begin{array}{l}\text { Limão cravo } \\
\text { Limão cravo e } \\
\text { citrumelo swingle }\end{array}$ & 17 & 80,96 \\
\hline
\end{tabular}

Fonte: Autores (2016)

Todos os produtores entrevistados informaram que destinam sua produção para vendas, sendo que $52,38 \%$ vendem para agricultores locais e de outros municípios, $47,62 \%$, além de venderem para agricultores locais e de outros municípios, também realizam vendas paras outros estados da federação. Cerca de $33,33 \%$ dos produtores informaram que além de venderem as mudas produzidas, utilizam-se destas para plantio agrícola em suas propriedades.

Cerca de $42,85 \%$ dos produtores possuem até $1 / 2$ tarefas $\left(1512,5 \mathrm{~m}^{2}\right)$ de área plantada com mudas cítricas, $28,58 \%$ possuem de 0,51 a 4 tarefas, acima de 4 tarefas $23,81 \%$ dos entrevistados e $4,76 \%$ não souberam responder. Quando questionados sobre a estrutura onde são produzidas as mudas, $85,71 \%$ dos agricultores informaram produzir suas mudas a céu aberto (no chão-chamada "raiz nua") e apenas $14,29 \%$ produzem em viveiros. 
De desacordo com a Instrução Normativa no 48 do MAPA (IN 48), publicada em 24 de setembro de 2013, que estabelece normas de produção e comercialização de material de propagação de citros e seus híbridos, válidas para todo o território nacional, todas as atividades de produção, incluindo produção de sementes, borbulhas e mudas deverão ser inscritas e fiscalizadas pelo MAPA, seguindo prazos, normas e requisitos técnicos específicos de cada etapa da produção (NETO et al., 2015).

A maioria dos agricultores, cerca de $90,48 \%$ não utilizam recipientes para a produção de mudas, sendo que as mesmas são semeadas e enxertadas no próprio campo e apenas $4,76 \%$ utilizam de tubetes na fase de sementeira e os outros $4,76 \%$ utilizam de sacos para produção (Figura 1).

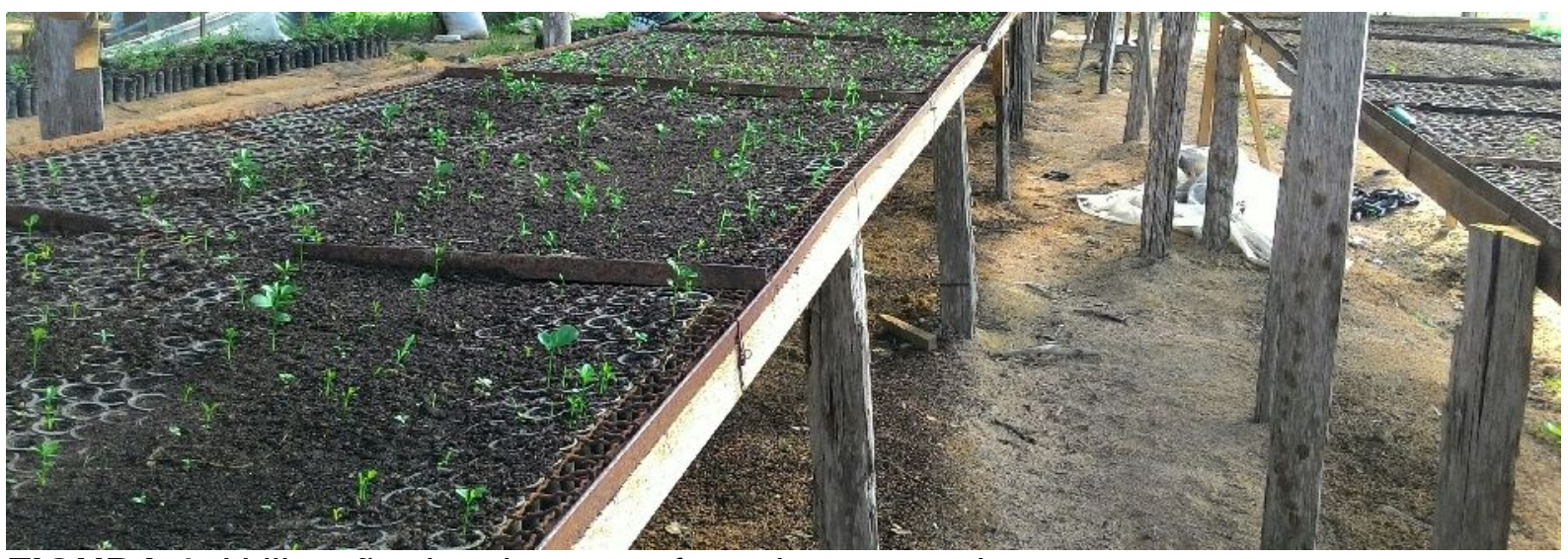

FIGURA 1. Utilização de tubetes na fase de sementeira.

Para $19,05 \%$ dos produtores, a fonte de água utilizada na irrigação é oriunda de rios/córregos, $57,15 \%$ de poços e $23,80 \%$ não utilizam sistema de irrigação na produção. Para os produtores que realizam irrigação $(76,20 \%)$ o sistema utilizado é o por aspersão (Figura 2).

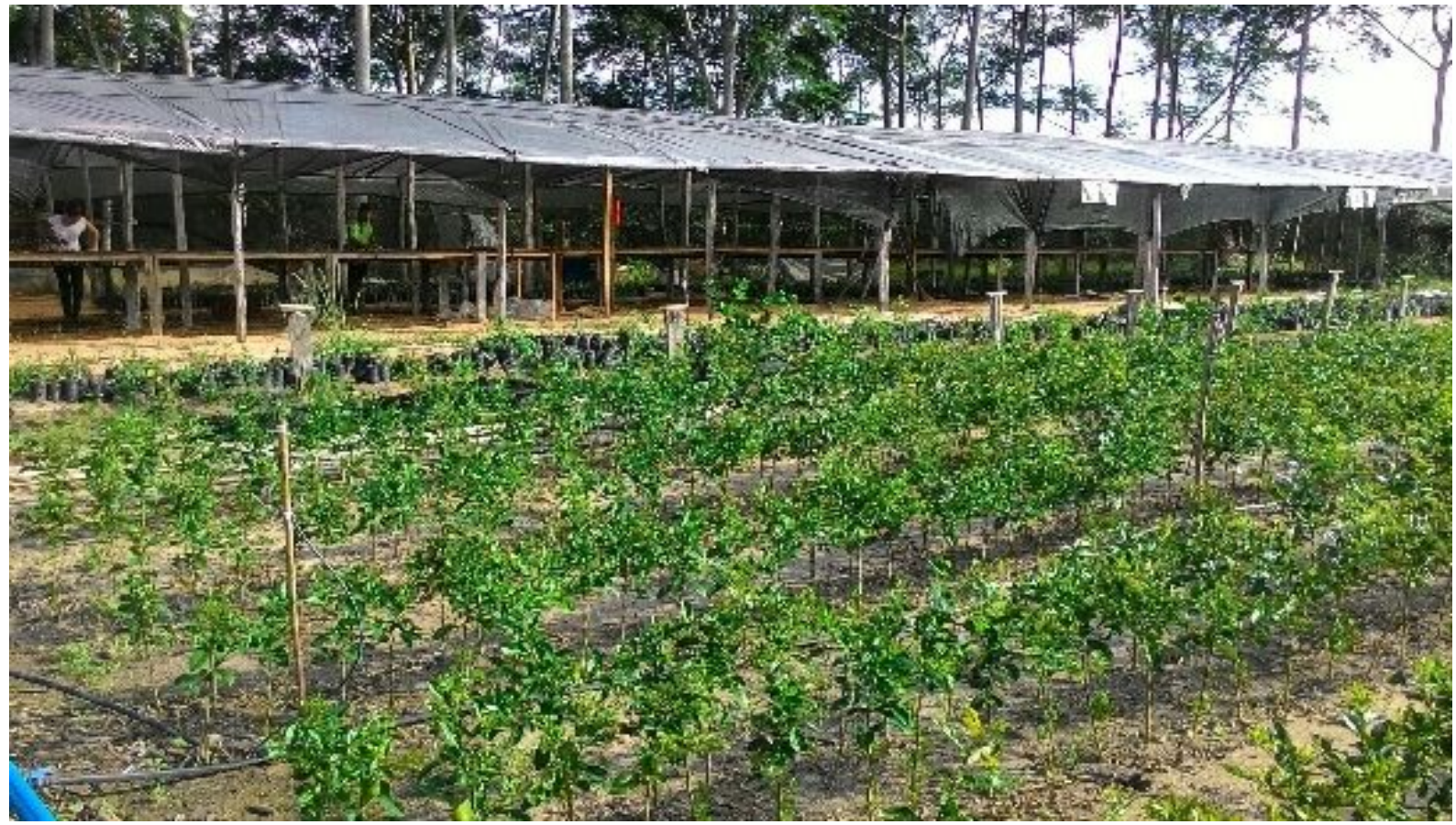

FIGURA 2 - Sistema de irrigação de mudas cítricas a céu aberto.

AGRARIAN ACADEMY, Centro Científico Conhecer - Goiânia, v.5, n.10; p. 1462018 
A Instrução Normativa no 48, de 24 de setembro de 2013 regulamenta a comercialização de mudas cítricas e que estas sejam produzidas em substratos que não contenha solo, que não haja contato com o solo e seja produzida e comercializada em recipientes (MAPA, 2013). Essa IN entrou em vigor no mesmo ano em que foi criada, dando prazo a todos os produtores de mudas cítricas do país a se regulamentarem de acordo com a lei até o ano de 2017 (Lei no 10.711).

A IN tem como propósito diminuir e evitar a dispersão de pragas e doenças de um local para o outro. Isso significa que, mudas produzidas no mesmo sistema detalhado nesse estudo, não poderão ser comercializadas com o vencimento do prazo de adaptação de sistema de produção. Segundo os produtores, a nova legislação para a produção e comercialização de mudas cítricas, é o principal desafio enfrentado por estes, somado a falta de área, pouco capital, assistência técnica falha e a falta de incentivo de políticas públicas. Muitos relataram que a falta de capital para investimento na estrutura de viveiro e insumos, seja um fator determinante para o encerramento das atividades.

\section{CONCLUSÕES}

O diagnóstico da produção de mudas cítricas na região indica que grande parte dos problemas são de ordem econômica, tecnológica, gerencial e de qualificação profissional no interior das unidades produtivas, que acarretam em dificuldades enfrentadas pelos mesmos para adequação a legislação, assim carecendo de soluções consistentes.

\section{AGRADECIMENTOS}

Os autores agradecem a todos os produtores de mudas cítricas da Comunidade de Santa Luzia do Induá, Capitão Poço-Pará pela disposição, dedicação e respeito ao se disponibilizarem a responder as perguntas.

\section{REFERÊNCIAS}

BRUGNARA, E. C; NESI, C. N; VERONA, L. A. F.; THEODORO, G. F.; KOLLER, O. L. Quantificação do cancro cítrico em tangerineiras enxertadas sobre diferentes porta-enxertos. Revista Brasileira de Ciências Agrárias, vol. 10, núm. 2, 2015, pp. 237-242. Disponível em: < http://www.redalyc.org/articulo.oa?id=119039562011>. doi: 10.5039/agraria.v10i2a5172.

DELUQUI, H. B. S., NEVES, S. M. A. S., SEABRA JÚNIOR, S., CARNIELLO, M. A., NEVES, R. J., COCHEV, J. S. Espaços produtivos da mandioca e seus usos em Cáceres-MT. Campo Território, v. 7, n. 14, p. 1-22, 2012. Disponível em: < http://www.seer.ufu.br/index.php/campoterritorio/article/view/14169/11194>.

EFROM, C.F.S., SOUZA, P.V.D. Citricultura do Rio Grande do Sul: indicações técnicas. Porto Alegre: Secretaria da Agricultura, Pecuária e Irrigação - SEAPI; DDPA, $1 . \quad$ ed, 2018. Disponível em: < http://www.agricultura.rs.gov.br/upload/arquivos/201805/15144652-citricultura-do-riogrande-do-sul-indicacoes-tecnicas-efrom-souza.pdf>.

FREITAS, W.; WANDER, A. E. O perfil socioeconômico da agricultura familiar produtora de hortaliças em Anápolis (GO, Brasil). Revista de Economia da UEG, 
v.13,

n.1,

2017.

Disponível

em:

http://www.revista.ueg.br/index.php/economia/article/view/5882/4619>.

IBGE - Instituto Brasileiro de Geografia e Estatística (2015). Cidades IBGE 2015. Disponível em: <https://cidades.ibge.gov.br/brasil/pa/capitao-poco/panorama>. Acesso em: 23 abr. 2018.

LOPES, E. B., BRITO, C. H., ALBUQUERQUE, I. C., BATISTA, J. L. Potencialidade do óleo de laranja no controle do pulgão preto dos citros. Revista Tecnologia Agropecuária. João Pessoa, v.3, n.2, p.23-26, 2009. Disponível em: < http://revistatca.pb.gov.br/edicoes/volume-03-2009/volume-3-numero-2-junho2009/tca04_oleo_laranja.pdf>.

MAPA-Ministério da Agricultura, Pecuária e Abastecimento (2013). Instrução Normativa no 48. Disponível em: http://www.agricultura.gov.br/assuntos/insumosagropecuarios/insumos-agricolas/sementes-e-mudas/publicacoes-sementes-emudas/INN48de24desetembrode2013.pdf>. Acesso em: 25 de jan. 2018.

NETO, H. B.; SILVA, S. R., MOURÃO FILHO, F. A. A., SPOSITO, M.B.; CAPUTO, M. M. Manual de boas práticas para produção de mudas cítricas. Araraquara: Vivecitrus. Organização Paulista de Viveiros de Mudas Cítricas, 69p, 2015. Disponível em: < http://vivecitrus.com.br/wp-content/uploads/2017/01/Boas-praticaspara-producao-de-mudas-citricas-.pdf $>$.

PACHECO, N. A., BASTOS, T. X. Análise frequencial da chuva em Capitão Poço, PA. Embrapa Amazônia Oriental, 16p, 2002. Disponível em: < https://www.infoteca.cnptia.embrapa.br/bitstream/doc/389602/1/OrientalDoc133.pdf>.

SÁ, L.A.N. Controle da larva-minadora-da-folha-dos-citros em pomares do país, $2005 . \quad$ Disponível em: <https://www.agencia.cnptia.embrapa.br/recursos/Sa_controleID-

Q6cXMWMiCw.pdf>. Acesso em 25 de jan. 2018.

SILVA, D. A. Caracterização do perfil socioeconômico e da percepção ambiental dos agricultores familiares dos assentamentos Dona Antônia e Gurugi II, no Conde, Paraíba. Revista Meio Ambiente e Sustentabilidade, v.12, n.6, 2017. Disponível em:

$<$ https://www.uninter.com/revistameioambiente/index.php/meioAmbiente/article/view/ 639/308>.

SOMBRA, K. E. S.; SILVA, A. C. C.; LOUREIRO, F. L. C.; UCHÔA, C. N. A citricultura como instrumento de preservação da agricultura familiar no semiárido cearense, Brasil. Revista de Extensão e Estudos Rurais. v.7, n.1, p.353-372, 2018. em:

https://www.revistarever.ufv.br/index.php/rever/article/view/168/92>.

SOUZA, M. FONTES, L. E. F.; LOPES, L. C. Avaliação de substratos para cultivo de crisântemo (Chrysanthemum morifolium Ramate., Compositae) White Polaris em vasos. Revista Brasileira de Horticultura Ornamental, v.1, n.2, p.71-74, 1995. Disponível em:

AGRARIAN ACADEMY, Centro Científico Conhecer - Goiânia, v.5, n.10; p. 1482018 
https://ornamentalhorticulture.emnuvens.com.br/rbho/article/view/94>.

doi:

https://doi.org/10.14295/rbho.v1i2.94 